\title{
Review of assisted reproduction techniques, laws, and regulations in Muslim countries
}

\author{
Chokri Kooli@
}

\begin{abstract}
Background: Fourteen Muslim countries were explored for available national laws, regulations, and guidelines concerning assisted reproduction techniques (ART). These documents were studied with total consideration of the ethical and religious principles followed by Islamic religion. This study found different types of legal documents issued by legislatives authorities, ethical committees, or professional bodies. Documents reviewed are directly related to assisted reproduction techniques medical use, access, or research in the field of ART.

Main body of the abstract: Most of the studied documents showed various degrees of deficiencies concerning legal or ethical protections and considerations. Certain documents that were examined need to be updated or amended in order to follow the continuous medical progress. The research also showed certain difficulty of legislating in countries characterized by multiculturalism and different ethical and religious traits and beliefs. Recently, Muslim legislators have made many efforts. However, the spread of legal documents among the Muslim countries is partial in volume and nature.

Short conclusion: The comparison of the content with international documents shows us that most of assisted reproductions legal documents in use in the studied countries demonstrate numerous deficiencies in term of structure, nature, and the coverage of controversial subjects.
\end{abstract}

Keywords: Assisted reproduction techniques, biomedical research ethics, Muslim countries, laws and regulations

\section{Background}

During the last three decades, we notified a fast growing research and development in term of human conception and manipulation of human genetic material for reproductive purposes. Researchers focused on inventing and finding new ways, technics, and solutions in order to improve the human well-beings. At the same time, this new situation and area of research opened the door to a huge ethical and legal debate. Scientists, politicians, researchers, and others always questioned what is ethically and/or legally acceptable or not acceptable. Research was always conducted under a climate of ambiguity because they did not observe clear lines prohibiting unacceptable applications of new human genetic and reproductive technologies. In addition, no legal or ethical context existed in order to allow beneficial applications

Correspondence: ibm4chk@yahoo.fr

Telfer school of Management, Ottawa University, Ottawa, Canada of the research and to proceed in a socially accountable manner. In order to regulate the dilemmas and resolve concerns, some countries developed comprehensive policies to govern human genetic and reproductive technologies. The UK, Germany, Australia, and Canada have laws on the books that prohibit unacceptable activities, require public oversight of acceptable activities, and establish socially accountable structures for revising policies or setting new ones. Policies adopted in these countries embody differing social and political values but agree on core principles. Lot of Muslim scholars admitted that a Muslim woman is entitled, and even expected, to seek medical fertility treatment and use new technologies in case she is childless. Muslim countries like Qatar and Saudi Arabia developed recently their own genome programs and focused research on human conception and manipulation of human genetic material for reproductive purposes. Therefore, given the importance and increasing utilization of assisted reproductive 
techniques in Muslim countries, professor Gamal Serour [1] was the first and most important Muslim scholar to study the ethical considerations of the ART. Professor Serour is an internationally renowned and oft-cited Egyptian physician with decades of experience working in reproductive medicine. He has authored numerous academic publications that draw on his clinical practice and role as advisor to Islamic regulatory and ethical bodies [2]. Recently, several scholars [3-6] highlighted the role of contemporary Islamic bioethics in addressing new issues and adopting new approaches for the sake of maintaining and improving the good health of humans. Researchers also strongly recommended that a national framework regulation be developed. There is a growing need for the elaboration of national standards in the complex and rapidly evolving field of assisted reproductive technology, particularly with respect to ethical and legal considerations. In such regard, researchers need to demonstrate that effective social governance of reproductive and genetic technologies can be secured in Muslim countries. The main objective of our paper is to check if Muslim countries developed substantial legislative controls on the spectrum of reproductive technologies used to assist in human conception and to manipulate human genetic material for reproductive purposes. Our paper will provide an overview of the current legislative landscapes in Muslim countries as well as an identification of the most important and relevant ethical considerations.

\section{Theoretical framework}

Encyclopedia and Dictionary of Medicine, Nursing, and Allied Health sterility [7] describe the condition of inability to produce offspring, i.e., either to conceive (females) or to induce conception (males). Contrarily to sterility, infertility is a revocable condition that is defined as the diminished or total absence of the ability to produce offspring, in either gender [8]. Medical progress made it possible to help infertile people to procreate through medical assistance. Infertility services conjugated by counselling, diagnostics, and treatments generally help people with fertility problems to find solutions to their reproductive plans [9]. Different terms were associated with the process of helping people to artificially have kids without following the natural and conventional process of procreation. Some researchers [10] used the term medically assisted reproduction (MAR). Other researchers [11-13] used the term assisted reproductive techniques (ART). In order to benchmark its outcomes, the International Committee for Monitoring ART (ICMART) [10] stressed the need for standard definitions of assisted reproductive technology. Ginsburg [12] qualified assisted reproduction as the jewel in the crown of reproductive medicine. For these researchers, it is one of the best examples in reproductive medicine of the transfer of knowledge obtained by laboratory scientists to an application that treats human disease. Assisted reproductive technologies include a set of methods used to achieve pregnancy with medical assistance [13]. From their side Scaravelli and Spoletini [11] admitted that ART include treatments where human gametes are handled outside the body to achieve a pregnancy. They include in vitro fertilization embryo transfer, intracytoplasmic sperm injection, gamete intrafallopian transfer, preimplantation genetic diagnosis oocyte and sperm donation, and surrogacy. Around the world, the question of having kids becomes an issue. Usually couples face cultural and social pressure in order to get kids as soon as possible. In certain societies, the delay of pregnancy is not acceptable and sometimes stressful. For Abu-Rabia [14], having children within Middle Eastern communities is expected, and not having children lowers social status. If a couple remains childless, it does not meet social desired expectations and does not obtain the higher status awarded to parents in their society. Thus, for these societies, the use of assisted reproductive technology becomes the perfect solution to the natural issue of the infertility and the dogmatic artificial social rejection. The appeal of the ART generated medical solutions for the treatment of infertility. It also created moral and ethical issues. Thus, as fixture of the societal landscape, assisted reproductive technologies and their potential uses challenged scientists, ethicists, religious scholars, governments, politicians, and society [15] and became controversial [16-19]. The main challenges reside in the complexity of the scientific information, the moral values associated with the subject, and the political dilemmas [20]. The Center for Genetics and Society made a research on the Canadian Assisted Human Reproduction Act and discovered that policies adopted in regard with ART are influenced by certain political values. The previously mentioned research also concluded that in several countries, the development of policy on human genetic and reproductive technologies has become deeply entangled with the politics of abortion, the "culture wars," and the presidential election. The moral values associated with the use of assisted reproductive technology are typically religious in nature. For Serour [21], it is therefore not surprising that science and religion have been interrelated since the beginning of human history. For him, science without conscience ruins the soul. From their side, Larijani and Zahedi [15] admitted that rarely a field of science caused debate and challenge because of religious concerns. The use of assisted reproductive technologies aroused different attitudes toward its morality in several religious and even within a particular religious tradition; there is a diversity of opinions [15]. In some parts of the world like the 
Middle East, behaviors, practices, and policies are usually influenced by the three main religions, namely Judaism, Christianity, and Islam [21]. Without exception, these religions encouraged procreation, family formation, and childbirth through natural conception within the frame of marriage [21]. In the Muslim world, religion still has a powerful meaning and greatly influences behavior, practices and policymaking [21]. Inhorn and Tremayne [22] considered Islam as a religion that encourages science, technology, and medical developments to overcome human suffering. For the mentioned researchers Islamic religion is seen as "pronatalist," and encouraging the growth of an Islamic "multitude". From his side, Gad El Hak and Serour [23] explained that treatment of infertility in married couples is encouraged in the Islamic religion, as it involves preservation of procreation. Islamic doctrine relays on the Quran, Assunnah Annabawiah, and the Islamic Sharia'a. An-Na'im, and Baderin [24] explained that Sharia'a is based on the Qur'an and things the Prophet Muhammad (PBUH) said and did. For him, Sharia'a was created by people who interpreted the Qur'an and the words and actions of the Prophet Muhammad (PBUH). As the world progresses, new issues and problems may arise, religious scholars could use Shari'a to try to figure out what people should do and get as close as possible to what the Prophet Muhammad (PBUH) would have said if he were still around [24]. An Islamic scholar, or mufti, could offer a religious ruling, or fatwa, based on his interpretation of Shari'a. A secular judge could then use the fatwa to make a legal ruling [24]. Doing so, it is clear that artificial reproduction constitutes a new emerging subject that was not mentioned in the primary sources of Sharia'a. However, several Islamic scholars issued fatwas legitimizing the recourse for the assisted reproduction techniques. These Fatwas come essentially from Dar El Iftaa [17]. In fact, in March 1980, his Excellency Sheikh Gad El Hak Ali Gad El Hak issued a Fatwa from Dar El Eftaa. It was the first ever issued guidelines that permit and regulate ART in the Muslim countries. That Fatwa was the background resource for all the regulations and guidelines issued in the Sunni Muslim world. It is appalling that such Fatwa with all its detailed guidelines on practices of ART, not known at the time, including surrogacy, egg donation, sperm donation, sex selection, cryopreservation, cloning, genetic manipulation for medical, and non-medical therapeutic indications was not widely disseminated globally. Following that, other Fatwas came respectively from the Islamic Organization for Medical Sciences in Kuwait, (1983), the Islamic Fikh Council, Mecca (1984), Qatar University (1993), the International Islamic Centre for Population Studies and Research [23, 25, 26], the Islamic Organization for Education, Science and Culture in Rabaat (2002) and the
United Arab Emirates (2002). These fatwas paved the way for medical practitioners to apply the new techniques of procreation on Muslims and in Muslim Countries. Therefore, these fatwas constituted a remedy to the failure of the natural procreation and an alternative solution to problems associated with adoption in Islam. In such regard, Islam encouraged treatment, and the cure of infertility becomes not only permissible, but also encouraged [27]. By encouraging treatment of an infertile couple, Islamic Sharia'a affirms the important statute of marriage, family, and procreation [28]. Despite the importance of Sharia'a and Islamic Fatwa, it was necessary for Islamic countries to adapt their legislative context to the medical progress and the assisted reproductive techniques and research in the area. Assisted reproduction was only widely accepted after prestigious scientific and religious bodies and organizations issued guidelines, which were adopted by medical councils and accepted by concerned authorities in different Muslim countries [21]; these principles have controlled the practices in assisted reproduction centers. So, as Islamic Sharia'a constitutes only a core of guidance and reference without having a legal force, a big concern raised among physicians providing ART. These health patricians worked generally without legal protection or guidance and faced several ethical dilemmas [21]. As part of the solution, a first International conference on Bioethics of Human Reproduction research in the Muslim world held on December 1991 was the first to look in ART from bioethical aspect and issued its guidelines that were an important resource for all Muslim countries in formulating their regulations and guidelines on assisted reproduction [25]. Furthermore, the Islamic Educational, Scientific and Cultural Organization (ISESCO) showed a deep interest regarding the research in the ART field. In fact, in 1993, the ISESCO issued the "Assisted reproductive technology-practice in ethical implications of advanced research in genetics [29]. Then, the same organization showed another interest regarding the research attached to the Human Embryo and Serour [30] published another original reference document for Muslim Scholars that was named "Ethical implications of human embryo research" [30]. The year after, an important workshop on bioethics in ART in the Muslim world was held in Cairo; Serour and Dickens [21] then published their recommendations. On the international side, the United Nations Educational, Scientific and Cultural Organization (UNESCO) adopted the Universal Declaration on Bioethics and Human Rights in 2005. It presented the "universal principles that will provide a foundation for humanity's response to the everincreasing dilemmas and controversies that science and technology present for humankind and the environment" [31]. This universal declaration encouraged Muslim 
countries to adopt new legislations that draw clear lines allowing and prohibiting acceptable and unacceptable applications of new human genetic and reproductive technologies. In fact, Muslim countries were encouraged to adopt and adapt their legislations in accordance with the medical progress and Islamic and societal principles. At this stage, a first hypothesis could be drowning. H1 supposes that Muslim countries adapted their legislative context to the medical progress about the assisted reproductive techniques.

The scientific progress observed among certain assisted reproduction techniques, generated certain practices that are not compatible with Islam and that are socially and ethically rejected [13]. The review of researches established in the field of assisted reproduction techniques allowed distinguishing some religious and ethical issues related respectively to the consent, sex selection, multiple gestations, surrogacy, maternal age, cryopreservation, and embryo research.

Nowadays, the medical development made it technically possible for parents to be able to select the sex of their future kids. While the UNESCO and several countries allowed the sex selection for medical reasons, they prohibited sex selection for social or familybalancing reasons. While the first choice is motivated by medical reasons that tend to protect the fetus and future generations, the second choice is discriminatory and could favor the selection of one sex comparing with the other and consequently affect the natural human sex determination process [32]. Recently, Dickens et al. [33] presented another approach for sex selection. For them "Prohibition of sex selection where discrimination is not pervasive is unnecessary; family balancing can be accommodated by allowing selection only where a family already has a child, or two or more children of the same sex" [33]. Another issue related to use of ART is conjugated in the potential risk of multiple gestations. The medical progress made it also possible to generate more eggs. The optimization of the probability of success of the assisted reproduction also needs the gestation and placement of more than one zygote in the woman uterus. All these medical advances optimized the chances of the success of the reproduction process but also accentuated the risk of having multiple gestations and consequently potentially risking the health of the mother $[9,13]$ and the fetus $[13,34]$. The primordial medical, ethical, and legal question that could be asked in such regard is directly linked to the maximum number of zygotes to be place in the woman uterus.

Research on embryos is also highly controversial in some countries and highly recommended in others. The main issues concern the conception of embryos for the sole purpose of research and the possibility to implant an embryo that has been subject to research [35]. Scientists believe about the importance of embryo research in the improvement of ART, but does this research interest prime on certain ethical considerations related to the embryo collection, disposal, and destruction?

Surrogacy in its gestational or traditional forms sparked a heated ethical debate. Surrogacy requires a third-party reproduction assistance. This preconception arrangement could be partial by borrowing sperm or oocytes in order to fertilize them in vitro and then implement them into the uterus of the biologic mother. The assistance could also be total, in such case; we use the sperm and oocytes of the biological parents, fertilize them in vitro, and then implant them into the uterus of a gestational carrier. The procreation method named surrogacy applied ethical considerations as it mitigate the concept of "biological lineage" or "the licit sex principle" [36] and takes form of trade and genetic exploitation.

Maternal age and pregnancy in the postmenopausal stage are not controversial in a natural biological relation between couples. However, when it comes to the use of assisted reproduction techniques, the age of the female becomes important. With the development of cryopreservation, it is now possible to have pregnancy in the post menopause using one's own cryopreserved embryos or even oocytes and possible in future cryopreserved ovaries [37]. The question of going against the human nature by allowing women to procreate after the menopause stage becomes an issue. Restricting women from having access to ART starting from certain age could be discriminating, given that there are no comparable laws restricting men from fathering a child using ART [13]. Allowing oldest women to procreate through ART could also affect the potential kids, as they potentially will not get the necessary care from vulnerable parents. In such situation, the child may experience psychological or social discomfort in having a mother who is old enough to be a grandmother [13]. Researches also showed that pregnancy at an advanced age increase the risks for complications that may threaten the safety of the offspring and women.

Medical advancement also made it possible to perform "cryopreservation" of gametes, zygotes, or embryos. The reason justifying the act could be personal or medical. In general, people with futile or poor prognosis of fertility and treating cancer or chronic medical illnesses make recourse to the technique of cryopreservation [13, 37]. This process will help them, if they desire, to procreate in the future in case they lose the natural capacity of having kids. Cryopreservation could also be performed in case of the embryo excess that were not used during a procreation cycle. After getting the consent of the 
couple, these embryos can be frozen for a certain period and returned to the uterus of the same woman whenever she decides to have a child [27]. The appropriateness of the method and the length of preservation were also subject to ethical debate. Nevertheless, the most controversial issue related to the cryopreservation is essentially linked to the continuity of the freezing process after the decease of one or both donators or in case of their separation [38]. The controversies regarding certain aspects of ART leaded us to draw a second hypothesis. H2 supposes that the laws and regulations proposed by the Muslim countries are up to date and covered all the controversial subjects related to the ART.

For the purpose of this paper, we will focus our analysis on certain Islamic countries laws and regulations in dealing with the ethical issues associated to the use of assisted reproduction techniques.

\section{Research framework and hypotheses development \\ Methodology}

This study uses a descriptive, analytical approach. The references adopted for the theoretical framework of this study are periodicals, books, and electronic articles. On the other hand, for fieldwork a documental collection and analysis was performed. In our study, we will perform a qualitative data collection method based on documental revision and analysis. This technique used existing and reliable legal documents and regulations of 14 Muslim countries. Bowen [39] admits that document analysis as a qualitative research method "is a systematic procedure for reviewing or evaluating documents-both printed and electronic (computer-based and Internettransmitted) material". This remind us that "the result of legislation review is summative as the emphasis is on evaluating whether Islamic countries found legal solutions to the controversial issues related to the assisted reproduction techniques application". Therefore, the method of research followed in this research will be the study of the different type of legal documents adopted by the Islamic countries in the context of ART. Taking into account this study's purpose, we will examine the degree of efficacy of laws and regulations adopted by Muslim countries in regulating the use of assisted reproduction techniques and dealing with its related controversies. Accordingly, our problem consist of exploring whether or whether not the studied Muslim countries succeeded to preserve the society ethical and religious principles and specifications in dealing with the controversial ethical issues generated by the medical progress in regard to the assisted reproduction techniques.
Population of study, data collection, and data analysis Muslim countries situated in the African, Asiatic, and European continent constitute the population of the study. The 14 countries were selected randomly based on the availability of legal data through peer reviewed, journals, and publications. We collected an important number of legal documents written in Arabic, English, and French. Then the content of these legal documents was analyzed and summarized through word. In particular, this study attempts to determine the causal relationship between the legislation of the different Muslim countries concerning the assisted reproduction techniques.

\section{Results}

Legislative progress of assisted reproduction techniques in Muslim countries

\section{Algeria}

The Law No. 18-11 dated the 2nd of July 2018 lays down fundamental provisions and principles and aims to give effect to the rights and duties of the population in the health matters. As part of this law, a chapter was dedicated to the Medical Assisted Reproductive Techniques. Thus, in Algeria, the access for the medical reproductive techniques is conditioned by the formal request of the legally married patients that are not capable to procreate naturally (Art.371). Under the provisions of this law, the donation, or sale of gametes, embryos, or sperm is strictly prohibited. In addition, the collection of embryos for the purpose of conducting studies and research are strictly forbidden (Art.374). The Law No. 18-11 also specified that the sex selection and human cloning are strictly prohibited (Art.375). A regulation regarding the storage of embryos and gametes is expected to be adopted soon. The 18-11 law regarding the Medical Assisted Reproductive Techniques was adopted recently, and the regulations connoted are not released yet. The comments and critics regarding these law and regulation will not be objective and effective.

\section{Bahrain}

His Majesty the King of Bahrain ratified and issued Law 26/2017 with respect to the use of medical techniques for artificial insemination and fertilization (MTAIF). Contrarily to Saudi Arabia, the definition of infertility is more general and inclusive. Under the dispositions of this law, infertility is the absence of pregnancy and therefore the inability of the couple to have children after the passage of 12 months from the continuous marital life in the marital home and without the use of contraceptives or pregnancy difficulties. Therefore, we understand from this definition that only married couples can get access to the medical techniques for artificial insemination and fertilization. The article 6 of the 
MTAIF law specify that the access for the medical techniques is conditioned by the formal consent and is subject to the continuity of the relation of marriage and its non-interruption by divorce or death. In addition, fertilized eggs may not be implanted in the uterus of another wife or any other woman. Likewise, the men's sperm cannot be used to fertilize other than the egg of his wife (Article 7). Human cloning and the collection of embryos for the purpose of conducting studies and research are strictly forbidden in Bahrain. Briefly, surrogacy is prohibited. The article 7 of the MTAIF law made it clear that only one embryo can be placed in the uterus of the female aged less than 35 years. Contrarily, patient aged over 35 years can receive up to 3 embryos, but the selective reduction of the embryos placed in the uterus through termination is only permitted in order to save the mother's life and after the approval of three medical consultants. Under the provisions of this law, the donation or sale of gametes or embryos is strictly prohibited. The use of stem cells extracted from a person to treat infertility in another person is not tolerable and results in prosecution. After having the formal acceptance of patients, the storage of sperm, eggs, and tissues is allowed for a period not exceeding 10 years. The storage of embryos is also allowed for a maximum period of 5 years (Article 8). The end of the marital relationship causes systematic destruction of the conserved gametes, sperms or embryos. The ninth article of the MTAIF has forbidden the establishment of embryonic or sperm banks in the Kingdom of Bahrain. It also specified that the import or export of embryos, sperm, or eggs is strictly prohibited from and to the Kingdom of Bahrain.

\section{Egypt}

The first ever-issued guidelines that permits and regulate ART in the Muslim countries were issued in Egypt. In fact, in March 1980, his Excellency Sheikh Gad El Hak Ali Gad El Hak, the Mofti of Egypt, issued a fatwa allowing the recourse to ART. This fatwa permitted treatment for Muslims but disallowed any form of third-party reproductive assistance, including surrogacy [40]. Since that, the use of assisted reproduction technology becomes popular and the In vitro fertilization (IVF) technique has become much more acceptable as a means of procreation among the medical community, patients, and society [41]. The large widespread of the ART among the Egyptian population was not followed by the issuance of laws regulating its use [42]. In fact, researchers Aboulghar et al. [43] estimated that breaking some religious laws might be more serious than breaking laws decided by the parliament. At the same time, Aboulghar et al. [43] assumed that the absence of laws could raise certain juridical and legal aspects. The year 1989 witnessed extensive discussion about the possibility of adoption of a law to regulate
IVF and intrauterine insemination (IUI). To guide the debate and give the experts point of view, a committee was formed. Its discussions reached a consensus and stated that IVF and IUI are legal and ethical procedures, and that centers offering such programs should follow the Islamic rules as stipulated in al-Azhar declaration on IVF and IUI [43]. Right now, "assisted reproduction is further addressed in the Professional Ethics Regulations of the Egyptian Medical Syndicate. These regulations, which amended previous regulations from 1974, have been issued by Decree No. 238/2003 of the Ministry of Health and Population (Ministry of Health Decree 238/2003) pursuant to the resolutions of the Egyptian Medical Syndicate Council and the General Assembly of Egyptian Physicians" [42]. The Decree No. 238/2003 specified that the sperm, egg and embryo donations are not permitted in Egypt (Art. 45). It also specified that in Egypt, gestational surrogacy is illegal. Art. 45 (2), 46, and 51 of the same decree, prohibit the establishment of egg, sperm, or embryo banks. They also ban the trade in human embryos. The Egyptian Society of Obstetrics and Gynaecology played also a certain role in regulating certain aspects of the ART. In fact, its Code of Ethics considered the cryopreservation of any surplus fertilized eggs and their implantation in a later cycle into the mother from whom the eggs come to be lawful [21]. The number of embryos to be transferred was restricted by certain local recommendations and guidelines. However, there are no regulatory mechanisms to control these guidelines, and IVF centers in general do not conform to recommendations concerning the number of embryos transferred [43].

\section{Jordan}

Since 2007, the Jordanian government presented a draft of a proposed law regarding the use of medical techniques to help reproduction. This bill is still subject for discussion in the parliament. Nowadays, we do not observe any specific law or regulation specially dedicated to the reproduction practices. Recently, the Jordanian government adopted the Law 25 of 2018 regarding medical and health accountability. This law integrated few articles that are directly linked to some artificial reproduction issues. Article 8 of this law criminalized human cloning, research, and experiments for cloning purposes. Under the provisions of article 13 of the same law, the application of the pregnancy aid technologies require the written approval of the married patients and also specified that embryos can be transplanted into the uterus of the women when the sperm is only obtained from her husband. According to the article, 14 of the law of medical and health accountability specified that women sterilization could not be performed, unless physicians get the written consent of the women concerned and a favorable approval of a medical committee. 
The Jordanian Stem cell bylaw of 2014 sets forth rules for the collection, storage, dispensing, and conduct of research on stem cells, including embryonic stem cells. It justified the need for stem cell research and/or therapy, stressed, and recommended the use of good medical practices to that end. Under its dispositions, research on embryonic stem cells is permitted only in public institutions. The third article of the bylaw announced the five categories of the legalized stem cells research including embryonic stem cells (ESCs), adult stem cells (ASCs), induced pluripotent stem cells (iPSCs), stem cells resulting from somatic cell nuclear transfer (SCNT), and cytoplasmic hybrid stem cells (Cybrid). While article 8 of this bylaw made it mandatory to have the formal consent of donators, the article 9 insisted that the collection and use of stem cells should be in accordance with Islam and Sharia'a law.

\section{Lebanon}

Like in Jordan, we do not observe any specific law or regulation specially dedicated to the reproduction practices in Lebanon. In 2016, the government proposed a bill on reproductive techniques assistance and research on the fetus. The project proposed is still under discussion in the parliament. A chapter regarding assisted reproduction techniques was introduced in the 1994 law of the medical ethics. The paragraph 6 of the article 30 of this law specified that only married couples, formally consenting, could resort to the artificial insemination or pregnancy by using assisted fertility techniques. The medical centers performing these acts shall take full due account of the laws in force in the civil, religious, sectarian, and spiritual courts. The eighth paragraph of the same article made it possible to perform research on stem cell research under certain specific conditions. The use of stem cell is also allowed contingent of respecting the conditions enumerated in the paragraphs 12 to 16 under the provisions of article 30 of the same law.

\section{Malaysia}

Malaysia is essentially considered as a Muslim country but also multiculturalist and multiethnic. In order to regulate the different legal and ethical issues related to the reproduction practices, Malaysian Medical Council (MMC) issued two main regulations. The first one is related to the assisted reproduction, and the second one concerns the stem cell research and therapy. First of all, in the Guideline 003/2006 related to assisted reproduction, the MMC recognizes that it is strictly prohibited to sell gametes, semen, or embryos. It also prohibited the reproductive cloning and the culturing of an embryo in vitro for more than fourteen days. Under these guidelines, assisted reproduction techniques must only be offered to married couples considering that they both formally consent to be involved in the process of treatment. This consent is also necessary in the case of disposal or further storage of genetic material for a period of 5 years that can be extended for one time. The stored gametes are systematically destroyed in the event of separation, divorced or decease. Under these guidelines, the technique of blastocyst transfer is ethically acceptable, and the embryos are allowed to grow beyond the typical 2-3 days of culture and are allowed to develop to the blastocyst stage before they are transferred to the womb [44]. The religious and cultural sensitivities of the patient and the medical practitioner play an important role in determining whether eggs, embryos, and sperms are donated to treat human subfertility in others with the help of assisted reproductive procedures. Such practices are not prohibited and are not allowed at the same time; they mainly relay on the beliefs of the patients and practitioners. The dispositions of the Guideline 003/2006 allow the sex selection of the embryos only if particular sex predisposes to a serious genetic condition. The MMC regulation recognized the importance of the prevention against the excessive multi-fetal gestation by restricting the numbers of embryo transferred and careful induction of ovulation. Despite that, the number of fetuses to be gestated was not clearly specified.

In 2009, the MMC issued Guidelines for Stem Cell Research and Therapy that was in line the same guidelines adopted by the Malaysian Ministry of Health. In such regard, under conditions of the conformity to the ethical guidelines, the local scientists and clinicians got the right of performing stem cell research. The two main conditions for conducting research on human embryonic stem cell consist of obtaining the informed consent of patients accepting to donate their gametes or blastocysts for free. The guidelines also specified what kinds of research are allowed or prohibited.

Despite the progress observed in the Malaysian legislation, the regulations adopted were typically issued by the Malaysian Medical Council and did not specify any penal dispositions in case of non-conformity to the law. A new regulation named the Artificial Reproduction and Tissue Act was supposed to be adopted in 2016, but it is yet delayed. In addition, when it comes to the process of storage and disposal of gametes and embryos, the regulations are vague and relay more on the intention of the practitioner rather than on clear and strict dispositions. The question of surrogacy is also indefinite and not clearly ruled. The recourse of such technique relays on the decision and religious beliefs of the patients.

\section{Morocco}

A first draft of law 47.14 regarding the Medical Assisted Reproductive Techniques was submitted in February 2016 and adopted in July 2018 by the Moroccan parliament. The 47.14 draft law specified that married couples; 
where natural conception has proven unfeasible for at least one year, have the full right for the use of reproduction methods and techniques, if they formally consent for that. At the same time, the proposed law clearly specified that persons that are proven completely sterile are not covered by its dispositions and consequently cannot seek procreation services. Doing so, those that have curable medical problem or that have medical evidence that they have poor fertility can get access to medical intervention resources under the dispositions of this law. The number of embryos to be injected in the uterus is going to be determined by special regulation.

Under the provisions of this draft law, the donation or sale of gametes, embryos, or sperm is strictly prohibited. In addition, the collection of embryos for conducting studies and research are strictly forbidden (Art.7). The draft Law No. 47.14 also specified that the sex selection and human cloning are strictly prohibited (Art.4).

The 2018 draft law strictly prohibited the industrial or commercial use of sperm, ovaries, and embryos (Article 6). Under the provisions of this law, the donation, sale, import, or export of gametes or embryos is strictly prohibited (Art.30). Briefly, surrogacy is strictly forbidden.

When it comes to the issue of the disposal or further storage of genetic material, the consent of patients becomes primordial. The bill proposed by the government suggested the possibility of storage of the sperm and ovaries for a period of 5 years that cannot be extended (Art.22). In the same context, the storage of the unused embryos is not possible. The stored gametes are systematically destroyed in the event of separation, divorce, decease, or under request of the patients. The Moroccan legislator took into consideration the society and human progress and made an exception regarding the storage conditions. Thus, people who are undergoing medical treatment that can affect their future possibilities of procreation are allowed to store their eggs or sperm for a period of 5 years that can be extended if judged necessary and motivated (Art.22). Despite the fact that the bill regarding the Medical Assisted Reproductive Techniques was recently adopted, the proposed draft seems to be inclusive and regulating the main conflictive contemporizing ethical issues. A better judgment regarding this law could be made once it is promulgated and completed by the joint regulations.

\section{Pakistan}

With the absence of system for ethical research clearance and in order to protect the interests of Pakistani people from harm and exploitation in the name of research, there was a need that the Health Research System of the country develops standards, procedures, and guidelines for the scrutiny of the ethical aspect of all health research being undertaken within the country. In 2004, the Ministry of Health constituted the National Bioethics Committee (NBC) that plays the role of the major, official body to uphold the bioethical principles in all sectors of healthcare in Pakistan. In 2016, the NBC adopted the Ethical Guidelines for Collection, Usage, Storage, and Export of Human Biological Materials (HBM). In addition, in collaboration with the human organ transplant authority, the NBC adopted the Protocol/Guidelines for Stem Cell Research/Regulation in Pakistan (SCRRP). The main objectives of the Protocol/ Guidelines adopted consisted of creating a framework for research and clinical applications of stem cells involving human subjects in strict accordance with the religious and social mores of the society. In addition, the SCRRP stressed the need to regulate the diverse aspects of stem cell research, therapy where the immense power to cure and rejuvenate is harnessed, and possible harm is avoided. Under the protocol/guidelines, physicians and health practitioners are not allowed to terminate the pregnancy for obtaining fetus for stem cells research or for transplantation. In addition, by reference to the same document, it is not allowed to create embryos for the sole purpose of obtaining stem cells. The guidelines contain also valuable instructions and dispositions that that guide researchers and health care practitioner in term of stem cell treatment and research. In general, under these guidelines shall be offered by authorized authorities, after getting the approval of patients and without having a trading purpose.

The second important document developed by the National Bioethics Committee of Pakistan discusses multiple aspects of Human biological Material (HBM) usage in medical research and provides ethical guidelines regarding collection, usage, storage, and export of HBM. The Ethical Guidelines for Collection, Usage, Storage, and Export of Human Biological Materials stressed the necessity of having a valid informed consent before performing any activity. It also highlighted the importance of maintaining confidentiality and privacy throughout the research process. Finally, it discussed the related commercial uses and benefit sharing. The National Bioethics Committee of Pakistan believes that HBM carries great significance in pharmaceutical industry where it can be used as raw material or as a precursor for research activities. For the National Bioethics Committee, these utilities have made the commercial use of HBM plausible and stressed the need to conceive suitable forms of compensation or benefit sharing.

Despite the importance of the protocol/guidelines adopted by the National Bioethics Committee of Pakistan, these dispositions lack the legal characters and the support of the government is essential in such 
regard. Thus, as example, the NBC strongly recommended that the Pakistani government make appropriate legislation for export of Human Biological Material. Our research also showed us that the Pakistani Government did not adopt any specific law or regulations, regulating the use of medical techniques for artificial insemination and fertilization.

\section{Qatar}

The Qatari Government did not adopt any specific law or regulations, regulating the use of medical techniques for artificial insemination and fertilization. Only research is regulated in such regard. Thus, the Qatar ministry of public health issued guidelines for human stem cell research and Qatar supreme council of health adopted the Guidelines, Regulations and Policies for Research Involving Human Subjects. The late mentioned document contained a chapter dedicated for reviewing additional Protections for Pregnant Women, Human Fetuses, and Neonates Involved in Research. In general, this policy highlighted the main conditions necessary to observe in order to perform research. It also offers guarantees to protect the health and safety of pregnant women, human fetuses, and neonates.

\section{Saudi Arabia}

As Malaysia, legal and ethical issues related to the reproduction practices are regulated in the medical and research contexts. Medically speaking, the Royal Decree No. M/76 dated march 2004 promulgated the Law of Units of Fertilization, Utero-Fetal, and Infertility Treatment. It clearly specified those people that are proven completely sterile are not covered by its dispositions. Doing so, those that have curable medical problem or that have medical evidence that their poor fertility can get access to medical intervention resources under the dispositions of this law. In addition, the Saudi law clearly specified that the access to the treatments be only guaranteed to those that have a proven existing marital relationship. Thus, divorce or death of one of the partners makes a termination for the process of fertilization and insemination. In addition, fertilized eggs may not be implanted in the uterus of another wife or any other woman. Likewise, the men's sperm cannot be used to fertilize other than the egg of his wife. Article 13 of the Saudi Law of Units of Fertilization, Utero-Fetal, and Infertility Treatment clearly specified that consent of the primordial formal consent of patients is necessary in order to conduct research on sperm, eggs, zygotes, or embryos. In 2014, the standing committee for research ethics on living creatures (SCRELC) defined the Law of Ethics of Research on Living Creatures Regulations: Implementing Regulations of the Law of Ethics of Research on Living Creatures (LERLC). Research establishment conducting research on living creatures in the Kingdom of Saudi Arabia must obey to the provisions of the Law and its Regulations. The LERLC strictly forbidden the trading in gametes, zygotes, organs, tissues, cells, or any parts thereof or genetic data related to human derivatives or products. The article 16 of the same law clearly specified the conditions under whom research on zygotes, gametes, or fetuses may be conducted. Article 18 of the LERLC specified that informed consent is necessary in order to conduct research on tissues, living cells, and separated parts, including stem cells extracted from the umbilical cord or adult stem cells. In all conditions, no research may be conducted for human cloning (Article 17).

\section{Sultanate of Oman}

In 2017, the Omani Ministry of Health issued the Fertility Centre Standards and Regulations for Private Sector. It intended to ensure a consistent, research based, and safe framework for the provision of assisted reproduction centers operating in Oman. Their main source of inspiration is the Sharia'a Law and Islamic rules and regulations as interpreted and implemented in the Sultanate of Oman. Under these regulations, the ministry of health established strict conditions in order to benefit from the fertility centers services. For example, pre-implantation genetic diagnosis (PGD) treatment is offered only to couple that are at risk of having a child with a serious genetic condition. The disorder, for which PGD is considered, has been identified in the family, and there is evidence that the future individual may be seriously impaired because of the disorder. Couples are admissible only if they do not have any living unaffected child from the current relationship and a qualified geneticist recommends that for PGD. Despite the respect of all the previously cited conditions, the female partner should be under 40 years of age at the time of PGD treatment. In general, fertility services providers are not allowed to perform non-medical gender selection. It is also prohibited to use donated sperm or eggs from a nonmarried couple. Again, a woman shall not be provided with any nonmedical fertility services involving the use of sperm other than her husband sperm. In all figures, the patient formal consent is needed in order to have access to treatment services involving the use of the gametes. Before the embryo transfer, female patients shall be offered by the center the opportunity to discuss, select, and formally consent the number of embryos to be transferred and accept the risk of having multiple births. In all cases, the regulations recommended the transfer of a maximum of two embryos to women under the age of 35 , and a maximum of three embryos to women aged 40 and over. The Omani Fertility Centre Standards and Regulations for Private Sector specified the conditions of storing unfertilized 
ova, sperm, and embryos. First, the formal consent of the patient(s) is necessary before performing the storage. Second, the preservation and storage is made for a maximum period of 5 years subject to the annual formal renewal and the non-decease of the patient. Finally, the Omani ministry of health clearly specified that the transportation of unfertilized ova outside the country is strictly prohibited.

\section{Tunisia}

The Tunisian government is considered as one of the first Muslim that legislated on the process of assisted reproductive technology in accordance with bioethics rules. The guarantee of the conformity with human rights at the start of life stage is governed by the law No. 2001-93 of the 7th of August 2001 on reproductive medicine. This act introduced the concept of reproductive health and prohibits genetic engineering, cloning, and the trafficking of fetuses and human embryos [45].

The articles 3 and 4 of the reproductive medicine law indicated that the access for the medical techniques is conditioned by the formal consent and is subject to the continuity of the relation of marriage and its noninterruption by divorce or death. The condition of marriage is not absolute as the unmarried patients suffering from diseases that could potentially affect their future reproductive capacities, were offered the opportunity to freeze their gametes. The future use of the frozen eggs or sperm is conditioned by the existence of legal relationship. In addition, the 2001 law indicated that fertilized eggs might not be implanted in the uterus of another woman. Likewise, the men's sperm cannot be used to fertilize other than the egg of his wife (Articles 14 and 15). Human cloning (Art.8) and the collection of embryos for conducting studies and research are strictly forbidden (Art.9) in Tunisia. The commercial conception and the industrial or eugenic use of human embryo is strictly prohibited (Art.7). Under the provisions of this law, the donation or sale of gametes, or embryos is strictly prohibited. After having the formal acceptance of patients, the storage of embryos and gametes is allowed for a period not exceeding 5 years renewable one time (Article 11). The end of the marital relationship or the request of patients causes systematic destruction of the conserved gametes, sperms or embryos.

Despite the progress observed in the Tunisian reproductive medicine law and its contemporary application, it appears that this law did not cover the issue of the number of embryos that could potentially be placed in the uterus of the female. This law neglected the ethical question of the security of the pregnant and the fetus. The issue of sex selection was not also treated.

\section{Republic of Turkey}

The first regulatory framework for assisted reproductive treatment was introduced in 1987 and prohibited the use of donor eggs, donor spermatozoa, and surrogacy [46]. In the 3rd of March 2010, the Turkish Ministry of Health adopted a new regulation on assisted reproduction therapeutic applications and assisted reproduction therapy centers. The regulations created a legal framework that helped to clarify the rules of access and use of infertility treatments throughout the nation. In addition, they assert a number of issues significantly affecting the practice of assisted reproduction. Through these regulations, only married couples that cannot have a child in natural ways, can benefit from the services of assisted reproduction. The use of eggs, sperms, and embryos out of the married couples is banned and the utilization of donors is prohibited. The new regulation also stipulated that the storage of the reproductive cells is prohibited with some exceptions in strict cases of medical obligations. The formal approval of storage of cells and tissues is yearly requested from the couple and is possible for a period not exceeding 5 years. The unused embryos are destroyed in case the couple formally refuses the renewal of the storage, in case of divorce, or in case of decease of one of the partners involved in the process. In order to care about the health of mother and baby and in order to prevent undesirable multiple pregnancies, the new regulations on assisted reproduction clearly specified the rules that apply in this situation. During the first and second tentative, physicians are allowed to implement only one embryo. This number is increased to two embryos for the following tentative. Patients aged over 35 years can receive a maximum of two embryos for each tentative. The sex selection for the embryo is prohibited, unless to avoid the risk of a specific genetic disease. In order to help the advancement of scientific knowledge and benefit of humanity, the Turkish new regulation on assisted reproduction therapeutic applications and assisted reproduction therapy centers allowed the performance of embryo research. In such order, researchers shall primordially obtain the agreement of the couples. The regulation also specified that research is allowed only for fourteen days postfertilization. Despite the progress observed in the regulatory framework for assisted reproductive treatment, the Turkish government started the process of amending the Law No. 2238 on the Harvesting, Storage, Grafting, and Transplantation of Organs and Tissues. The legislators are intended to outlaw the surgical implantation of a fertilized egg for carrying the fetus to term for another woman. Having a child or serving as a surrogate mother is strictly prohibited. Despite the small progress observed in term of research regulation, the legal context still blocks the scientific research [47]. 


\section{United Arab Emirates}

In the United Arab Emirates, the Federal Law No. regulates the recourse for the Assisted Reproductive Techniques. (11) Of 2008 Concerning Licensing of Fertilization Centers in the State, the Cabinet Decision No. (36) Of 2009 Issuing the Implementing Regulation of Federal Law No. (11) Of 2008 and the 2014 HAAD Standard for Assisted Reproductive Technology Services and Treatment. The 2008 federal law specified that married couples, where corporeal conception has proven unfeasible for at least 1 year, have the full right for the use of reproduction methods and techniques, if they formally consent for that (Article 9). Article 10 of the same law clarified that all the possible forms of surrogating are strictly forbidden. In addition, the 2008 law strictly prohibited the commercial use, genetic modifications or the performance of research on the collected and unused sperm, ovaries, and embryos (Article 14). In order to limit the risk of having multiple births, the Emirates legislators limited the number of embryos or ova to be transferred to a maximum of three, if the wife is aged 35 years or under. In all other cases, a maximum of four embryos was settled. In addition, the 2008 law clarified the process and conditions of preservation of the unfertilized ova and sperm. So, after having the formal consent of the married patients, the unfertilized ova and sperms are preserved for future reproduction for a maximum period of 5 years that is renewed annually. The request, divorce, or the decease of the patients systematically results in the destruction of the collected ova and sperms (Article 13). The import or export of specimens of unfertilized or fertilized ova or sperms inside or outside the state is also strictly prohibited (Article 18). Despite its visible effectiveness, the 2008 federal law did not rule the freezing of unfertilized eggs extracted from unmarried females. A practice facilitating the freeze of eggs, in UAE, was observed between 2008 and 2011. However, starting 2012, the UAE ministry of health banned the practice of storing frozen embryos. Again, recently, based on a case-by-case review, the same ministry allowed some unmarried females to freeze their eggs in order to use them in case of need. According the National UAE newspaper, a cabinet decision will give the unmarried women and couples the opportunity to freeze their embryos and eggs under certain conditions and in specific circumstances.

\section{Discussion}

The aim of our study consisted of examining the degree of efficacy of laws and regulations adopted by Muslim countries in regulating the use of assisted reproduction techniques and dealing with its related controversies. The central research question of the study was do Muslim countries succeeded to preserve the society ethical and religious principles and specifications in dealing with the controversial ethical issues generated by the medical progress concerning the assisted reproduction techniques? We drew on assisted reproduction techniques literature in order to develop our propositions that served as guidelines and theoretical framework for our empirical study. The data revealed two dominant themes: the adaptation of the legislative context and the efficacy of the legal dispositions.

The generated themes were used to structure the presentation of our findings. Below we link the two main themes to the formulated propositions in order to present our conclusions. Related to our first proposition, Muslim countries adapted their legislative context to the medical progress concerning the assisted reproductive techniques; we can conclude that the majority of the studied countries showed an interesting level of awareness regarding the subject studied. Consequently, the majority of these countries legally regulated the research and practice of the assisted reproduction techniques. The findings show that the studied countries are fully aware about the importance of the ART in maintaining the family unit and the social cohesion. At the same time, these countries are aware about the challenges resulting from the medical progress and consequently took legal dispositions that protect the social statute of the family according to the society principles, ethically acceptable behaviors, and Islamic principles. Given the role of assisted reproduction techniques, the necessity of legislation the medical progress according to the society ethical and moral principles and standards is an important first finding.

Second, the findings show that it is important to regularly update laws and regulations in order to follow the fast medical progress of the assisted reproduction techniques. This is reflected in our second proposition: The laws and regulations proposed by the Muslim countries are up to date and covered all the controversial subjects related to the $A R T$. Regularly updating the legislative context permits the Muslim countries to follow the medical progress and help guide the medical practitioners by showing them what is ethically and socially acceptable. The analysis of the laws and regulations adopted by Muslim countries are not updated and do not cover all potential emerging conflictual points.

These findings suggest a significant and relevant assimilation of responsibilities, seriousness, and awareness towards the legal dispositions regulating the research and access to the assisted reproduction techniques among the Muslim countries. In other words, the very different agendas and concerns of the Muslim countries regarding ART legislation could potentially affect the social cohesiveness, negatively change the structure of family, and destroy lineage. These findings suggest also a 
continuous, significant, and relevant legal work in total collaboration with scientists and Islamic scholars towards the policies, laws, and regulations making in the area of assisted reproduction techniques. In other words, the collaboration between these actors will lead to a better improvement of the actual and future well-being of Muslim families and will protect the social cohesiveness of Muslim societies by guaranteeing the preservation of ethical and moral values.

Additional findings provide more insight into how the adopted legal dispositions help to draw an idea about the general efficiency of the studied countries. They also help those who perform the effort of analysis to understand the different orientations, strengths, and weakness of the legal framework of the ART in the Muslim countries. The additional findings show that out of 14, only four countries adopted or updated their laws in the last 2 years. Indeed, the Kingdom of Bahrain and the Sultanate of Oman promulgated laws related to the assisted reproduction in 2017. Laws of Algeria and Morocco were promulgated in 2018. A set englobing 4 countries shows that their laws are considered ancient in regard to the fast growing of the medical progress in the field of ART. Indeed, the Tunisian law of reproductive medicine was promulgated in 2001. The Saudi Arabia Law of Units of Fertilization, Utero-Fetal, and Infertility Treatment was promulgated in 2004. The United Arab Emirates law on Licensing of Fertilization Centers in the State was promulgated in 2008. Finally, the Turkishassisted reproduction therapeutic applications and Turkish-assisted reproduction therapy centers law were updated and promulgated in 2010. Thus, we understand that these countries did not update their laws since long period. The fast medical progress in the field of study needs a parallel real-time update of the legal context. This will offer additional benefits to families and facilitate work of medical practitioners. Data analysis also shows us that three countries proposed bill regarding laws regulation ART (Malysia and Lebanon in 2016 and Jordan in 2007). Unfortunately, this proposed legislation is still under discussion and were not yet promulgated. The delay in the discussion and promulgation shows us the importance and sensibility of the subject. In the same context, we also notified that Qatar and Pakistan did not legislate the access and use of assisted reproduction techniques. The medical practitioners relay more on the Sharia'a dispositions and Islamic scholars' fatwas. At the same time, these two countries issued separate regulations regarding the Human stem cell research and Research Involving Human Subjects. The step followed by these two countries has an important consideration as the policy makers in these countries believe that research in this area can also help in developing the knowledge related to ART and consequently improve the well-being of families. While Saudi Arabia, Malaysia, and Jordan allowed the embryos research under certain conditions, countries like Tunisia and Morocco Strictly made it forbidden. More findings related to the form of the regulations adopted by the studied countries shows us that while the majority of the countries adopted laws and regulations that are exclusively dedicated to the thematic of assisted reproduction techniques, other countries like Jordan an Algeria had chosen to make articles related to ART as chapters of other related laws. In the majority of cases, the governmental policy makers took in charge the responsibility of conceiving and adopting laws and regulations. This finding is not absolute as in countries like Egypt, Pakistan, Malaysia, and Saudi Arabia the regulations related to assisted reproduction practice, and the research were issued by ethics committees and professional bodies. A last finding related to the form of the laws and regulations made it possible to conclude that the legislators of certain countries (Malaysia, Lebanon) took into considerations certain ethnic, cultural, and religious sensibilities and gave certain flexibility to the patients and medical practitioners in dealing with certain controversial issues related to the performance of the assisted reproduction technics. When we focus the analysis on the content of laws and regulations, we notify that the recently adopted laws (Bahrain, Morocco and Oman) are more inclusive and dealt with the contemporary issues related to the research subject. The Algerian law was adopted in 2018, but it was not a law exclusively dedicated to the ART. The analysis of articles adopted in such regard clearly indicate that this chapter missed or ignored several sensitive thematic directly related to the subject. Thus, we conclude that the comprehensiveness and efficiency of legal documents related to the assisted reproduction techniques essentially depend on their nature. The autonomy of laws and regulations in the field of ARD is highly recommended.

Today the basic guidelines for ART in the Muslim countries indicate that the application of ART is only allowed in a married couple and during the validity of marriage contract with no mixing of genes [37]. Divorce or death mark the end of the marriage relation; thus, in 2000, the International Islamic Center for Population Studies and Research at AL Azhar University admitted that in such situation procuring pregnancy in an unmarried woman is forbidden by religious laws. This Fatwa and the different consulted legislations did not pronounce on the situation where the couple started the process of artificial insemination and the husband decided during the period of gestation and before the final step of implantation of the embryo in the uterus of the woman. In such case, is it ethically and religiously acceptable? The Grand Mofti 
of Cairo in a personal communication with Prof. Gamal Serour had given permission for embryo implantation in a wife following a very recent husband's death based on the circumstances of the particular case. However, he clearly indicated this should not be taken as generalization and each case should be considered on its own merits [48].

Another controversial subject related to ART was not fully covered by the studied legislations. The maternal age is ethically important, but none of the studied countries fixed the limit of the age of the female candidate for the assisted reproduction. It seems also that the Islamic religious scholars did not take position on such situation. This case is frequent especially with the cases of embryos excess that were frozen or in case of the preventive freezing of gamete for medical purposes. A unanimity was observed regarding the possibility of reducing the number of the implemented fetuses in case of threat for the mother or the baby. However, at the same time, the reviewed laws and regulation show us lot of differences between countries about the number of embryos to be placed in the women uterus. Some countries did not even specify the maximum number embryos to be placed or left choice for the medical practitioner or the patient. View to the importance of the protection of the health of the mother or the security of the fetus, it is highly recommended that the legislators take into consideration the importance of the specification of the maximum number of embryos to be placed. Taking care about the age of the mother is a factor that needs to be taken into consideration. The cryopreservation of gametes and embryos is ethically and religiously acceptable in Islam, but length of freezing was not subject of unanimity in the studied countries. The minimum of 5 years of preservation was observed in all evocated cases. The possibility of extension was not always possible, and whenever it is permitted, it is subject of consent. The request, the death, and the separation of patient(s) are generally systematic causes of destruction of the preserved material. Another finding related to sex selection showed sex selection for family-balancing reasons is controversial. Nevertheless, at the same time, the screened laws and regulations allow the sex selection for medical reasons. Despite the importance of the last position adopted by the studied countries, a deep analysis of the legislation shows us that the term of medical reason is vague and subject to interpretation and possibly abuse from certain medical practitioners. We highly recommend that the policy makers in consultation with medical specialists clearly specify the medical situations to whom it is allowed to perform sex selection. It is also highly recommended that a committee and not a single person shall make such decision. All these special dispositions can prevent medical abuse of practitioners and vulnerable families. There is a significant body of literature on the degree of efficacy of laws and regulations regulating the use of assisted reproduction techniques and dealing with their related controversies $[9,13,17$, $20,49,50]$. Only few significant researches also studied the impact of laws and regulations but this time in Muslim societies [46, 47, 51, 52]. To the best of our knowledge, only two researches were made in a comparative context. The first one was conducted by Alahmad et al. [53] and consisted of reviewing the national research ethics regulations and guidelines in Middle Eastern Arab countries. The second one was conducted by Inhorn et al. [54] and studied assisted reproduction in a comparative regional context between four countries. Given increased fast medical progress, societal pressures, infertility challenges, and ethical and religious concerns, future research could pay more attention to the efficacy of laws and regulations regulating the use of assisted reproduction techniques in a global and regional context. Many of ART challenges can only be solved if we focus on common Islamic values and principles in an extended and unified way of legislation. Many voices raised and applied for the regulation the issues related to research, access, and use of assisted reproduction techniques. Our study summarized the legislative progress observed in 14 Muslim countries in different continents, with ethical, religious, and societal convergent and divergent values. We also tried to explain how legislations of the studied countries dealt with the fastest medical progress and the emerging controversies related to the assisted reproduction techniques. As the majority of similar researches were conducted on laws or regulations of a single country, it is unsafe right now to compare our results to the existing knowledge in the same area.

We tried to demonstrate that Muslim countries made an important progress in term of legislating the assisted reproduction research, access and use. Unfortunately, we partially approve this hypothesis as despite the fact that the research showed us that the majority of countries adopted laws and regulation related to ART, still certain countries did not do the same. In certain cases, legislators focused only on regulation the research area and left the issues of access and use officially unregulated, under the control of the medical practitioners or under the authority of ethics committees and professional bodies. We also concluded that certain government showed the willingness to legislate the field of the research, but the proposed bill takes long time to be promulgated.

In summary, we suggest more impact ART laws and regulations research in a global context and on the different aspects of research, use, and access. We highly recommend performing researches in a comparatives context with an explicit focus on the controversial aspects that were religiously accepted by Islamic scholars. 
In addition we want to make a strong plea for taking into account the crucial role of collaboration between the legislating bodies, medical authorities, and Muslim scholars [55] in term of adopting laws and regulations based on Islamic and ethical principles and in total concordance with the Islamic society needs and families emancipation.

Our empirical findings offer various clues for the effective implementation of laws and regulations based on medical, ethical, and religious principles. Secondly, our research findings hint at the importance of the serious consideration and balancing between the fast medical progress, Islamic society values, and family needs in the assisted reproduction techniques context. Thirdly, it is recommendable for Islamic policy makers to focus more on taking advantage from the legislative experiences of similar countries and continue the legislating efforts and continuous updating of laws and regulations in strict collaboration with the medical practitioners and religious scholars.

\section{Conclusion}

The regulations of the studied Muslim countries in the field of assisted reproduction techniques are mitigated and their importance form and content differ from one country to another. In this study, the focus is on the efficacy of laws and regulations adopted by the Muslim countries in regulating the use of assisted reproduction techniques and dealing with its related controversies. The findings reveal new insights in a regional religious comparative context. Findings and insights can also be relevant for policy makers of the reproduction-assisted techniques in different ethnic and religious contexts in countries and regions around the world.

\section{Abbreviations}

ART: Assisted reproduction techniques; ASC: Adult stem cells; Cybrid: Cytoplasmic hybrid stem cells; ESC: Embryonic stem cells: HAAD: Health Authority Abu Dhabi; HBM: Human biological materials; IPSC: Induced pluripotent stem cells; ISESCO: Islamic Educational, Scientific and Cultural Organization; IUI: Intrauterine insemination; IVF: In vitro fertilisation; LERLC: Law of Ethics of Research on Living Creatures; MAR: Medically assisted reproduction; MMC: Malaysian Medical Council; MTAIF: Medical techniques for artificial insemination and fertilization; NBC: National Bioethics Committee; PBUH: Peace be upon him; PGD: Preimplantation genetic diagnosis; SCNT: Somatic cell nuclear transfer; SCRELC: Committee for research ethics on living creatures; SCRRP: Stem Cell Research/Regulation in Pakistan; UAE: United Arab Emirates; UNESCO: United Nations Educational, Scientific and Cultural Organization

\section{Acknowledgements}

Not applicable.

\section{Authors' contributions}

The author read and approved the final manuscript.

\section{Funding}

No funds were provided for the production of this article.
Availability of data and materials

Not applicable.

Ethics approval and consent to participate

Not applicable.

\section{Consent for publication}

Not applicable.

\section{Competing interests}

The author declare that he has no conflict of interest.

Received: 12 October 2019 Accepted: 21 November 2019

Published online: 11 December 2019

\section{References}

1. Serour Gl (1994) Islam and the four principles. In: Gillon R (ed) Principles of Health Care Ethics. John Wiley \& Sons Ltd, London, pp 75-91

2. Monroe K (2019) Muslims and assisted reproduction. In: Woodward M, Lukens-Bull R (eds) Handbook of Contemporary Islam and Muslim Lives. Springer, Cham

3. Ghaly M (2013) Islamic bioethics in the twenty-first century. Zygon ${ }^{\circledast} 3(48)$ : 592-599

4. Alali K, Serour G, Bagheri A (2017) Challenges in Islamic bioethics. Islamic Bioethics: Current Issues And Challenges 2:229

5. Chaabna K, Cheema S, Abraham A, Alrouh H, Mamtani R, Sheikh JI (2018) Gray literature in systematic reviews on population health in the Middle East and North Africa: protocol of an overview of systematic reviews and evidence mapping. Systematic reviews 7(1):94

6. Serour Gl, Serour AG (2019) The Islamic perspective: application of advanced reproductive technologies to screen human embryos during IVF. In: Human Embryos and Preimplantation Genetic Technologies. Academic Press, pp 85-93. https://www.sciencedirect.com/science/article/pii/B978012 8164686000102

7. Miller-Keane Encyclopedia and Dictionary of Medicine, Nursing, and Allied Health, Seventh Edition. (2003). Retrieved August 272018 from https:// medical-dictionary.thefreedictionary.com/sterility

8. Stedman's medical dictionary (2000), 27th ed. London \& New York: Lippincott Williams \& Wilkins.

9. Soini S, Ibarreta D, Anastasiadou V, Aymé S, Braga S, Cornel M, Harper J (2006) The interface between assisted reproductive technologies and genetics: technical, social, ethical and legal issues. European Journal of Human Genetics 14(5):588

10. Zegers-Hochschild F, Adamson GD, de Mouzon J, Ishihara O, Mansour R, Nygren K et al (2009) The international committee for monitoring assisted reproductive technology (ICMART) and the world health organization (WHO) revised glossary on ART terminology, 2009. Human reproduction 24(11):2683-2687

11. Scaravelli G, Spoletini R (2015) The application of reproductive techniques (ART): worldwide epidemiology phenomenon and treatment outcomes. In: Ronald Ross Watson Handbook of Fertility, pp 75-87 https://doi.org/10. 1016/B978-0-12-800872-0.00007-X

12. Ginsburg, S. E., \& Racowsky, C. (2014). Yen \& Jaffe's reproductive endocrinology e-book: assisted reproduction, Elsevier Health Sciences. Pages 734-773.e12. https://doi.org/10.1016/B978-1-4557-2758-2.00031-7.

13. O'Neill S, Blackmer J (2015) A Canadian Medical Association white paper: assisted reproduction in Canada (an overview of ethical and legal issues and recommendations for the development of national standards). Canadian Medical Association, Ottawa

14. Abu-Rabia A (2013) Infertility and surrogacy in Islamic Society: socio-cultural, psychological, ethical, and religious dilemmas. The Open Psychology Journal 6(1)

15. Larijani, B., \& Zahedi, F. (2004). Islamic perspective on human cloning and stem cell research. In Transplantation Proceedings (Vol. 36, No. 10, pp. 3188-3189). Elsevier

16. De Mouzon J, Allavena E, Schmitt C, Frappé M (2004) La fécondation in vitro en France. Approche économique et influence du choix des gonadotrophines (urinaires ou recombinantes) sur le coût. Gynécologie obstétrique \& fertilité 32(6):508-518 
17. Nelson EL (2005) Comparative perspectives on the regulation of assisted reproductive technologies in the United Kingdom and Canada. Alta. L. Rev. 43:1023

18. Adamson GD, de Mouzon J, Lancaster P, Nygren KG, Sullivan E, ZegersHochschild F (2006) International Committee for Monitoring Assisted Reproductive Technology

19. Dickey RP (2007) The relative contribution of assisted reproductive technologies and ovulation induction to multiple births in the United States 5 years after the Society for Assisted Reproductive Technology/American Society for Reproductive Medicine recommendation to limit the number of embryos transferred. Fertility and sterility 88(6):1554-1561

20. Caulfield T, Knowles L, Meslin EM (2004) Law and policy in the era of reproductive genetics. Journal of medical ethics 30(4):414-417

21. Serour Gl (2008) Islamic perspectives in human reproduction. Reproductive BioMedicine Online 17:34-38

22. Inhorn MC, Tremayne S (2016) Islam, assisted reproduction, and the bioethical aftermath. Journal of religion and health 55(2):422-430

23. Gad El Hak, A. G. E., \& Serour, G. I. (2000). Some gynecological problems in the context of Islam. The International Islamic Center for Population Studies and Research.

24. An-Na'im A, Baderin, e. (2006) Islam and Human Rights: selected essays of Abdullahi An-Na'im. Routledge, London. https://doi.org/10.4324/ 9781315251790

25. Serour Gl, Omran A (1992) Ethical guidelines for human reproduction research in the Muslim world. International Islamic Center for Population Studies and Research. Al-Azhar University, Arabic and English

26. Serour Gl (1997) Ethical implications of assisted reproductive technology in the Muslim world. International Islamic Center for Population Studies and Research. Al Azhar University, Cairo

27. Al-Bar MA, Chamsi-Pasha H (2015) Assisted reproductive technology: Islamic Perspective. In: Contemporary Bioethics. Springer, pp 173-186. https://www. ncbi.nlm.nih.gov/pubmed/25660098.

28. Serour G (1998) Reproduction choice: a Muslim perspective. In: Harris J, Holm S (eds) The Future of Human Reproduction: Ethics, Choice and Regulation. Clarendon Press, Oxford

29. Islamic Organization of Education, Science and Culture (ISECO) (1993). Ethical reflection of advanced genetic research, Doha.

30. Islamic Organization of Education, Science and Culture (ISESCO). Serour, (2000), editor G. I. Serour. Ethical implications of human embryo research. Available at http://archive.isesco.org.ma/templates/isesco/publications/en/ Human\%20Embryo/humanEm.php

31. UNESCO (2006) Universal declaration on bioethics and human rights, Paris http://unesdoc.unesco.org/images/0014/001461/146180E.pdf

32. Fathalla MF (2000) The girl child. International Journal of Gynecology \& Obstetrics 70(1):7-12

33. Dickens BM, Serour GI, Cook RJ, Qiu RZ (2005) Sex selection: treating different cases differently. International Journal of Gynecology \& Obstetrics 90(2):171-177

34. Adashi EY, Barri PN, Berkowitz R, Braude P, Bryan E, Carr J et al (2003) Infertility therapy-associated multiple pregnancies (births): an ongoing epidemic. Reproductive biomedicine online 7(5):515-542

35. Jones H Jr, Cohen J (2004) IFFS surveillance 04. Fertility and sterility 81(4):S9-S54

36. Shabana, A. (2013). Law and ethics in Islamic bioethics: nonmaleficence in Islamic paternity regulations: with Mohammed Ghaly,"Islamic Bioethics in the twenty-first century"; Henk ten Have,"Global Bioethics: Transnational Experiences and Islamic Bioethics"; Amel Alghrani,"Womb Transplantation and the Interplay of Islam and the West"; Shoaib A. Rasheed and Aasim I. Padela,"The Interplay between Religious Leaders and Organ Donation among Muslims"; Aasim I. Padela,"Islamic Verdicts in Health Policy Discourse: Porcine-Based .... Zygon ${ }^{\oplus}$, 48(3), 709-731. https://doi.org/10.1111/zygo.12041

37. Serour GI (2005) Religious perspectives of ethical issues in ART. Middle East Fertility Society Journal 2005 10(3):185-190

38. Dolgin UL (1997) Defining the family: law, technology, and reproduction in an uneasy age. NYU Press

39. Bowen GA (2009) Document analysis as a qualitative research method. Qualitative research journal 9(2):27-40

40. Inhorn MC, Patrizio P, Serour GI (2010) Third-party reproductive assistance around the Mediterranean: comparing Sunni Egypt, Catholic
Italy and multisectarian Lebanon. Reproductive BioMedicine Online 21(7):848-853

41. Mansour RT, Abou-Setta AM (2005) Assisted reproductive technology in Egypt, 2001: results generated from the Egyptian IVF registry. Middle East Fertility Society Journal 10(2):87-93

42. Buchler A, Kayasseh ES (2014) Medically assisted reproduction in Egypt, Iran Saudi Arabia and the United Arab Emirates: Sunni and Shia Legal Debates. Eur. JL Reform 16:430

43. Aboulghar M, Serour Gl, Mansour RT (2007) Ethical aspects and regulation of assisted reproduction in the Arabic-speaking world. Reproductive BioMedicine Online 14:143-146

44. Malaysian Medical Council. (2006). guideline of the Malaysian medical council mmc guideline 003/2006 assisted reproduction.

45. UN (2007). Consideration of reports submitted by States parties under article 40 of the Covenant: International Covenant on Civil and Political Rights: 5th periodic report: Tunisia, http://dag.un.org/bitstream/handle/111 76/266000/CCPR_C_TUN_5-EN.pdf? sequence $=1$ \&isAllowed $=y$

46. Gürtin ZB (2011) Banning reproductive travel: Turkey's ART legislation and third-party assisted reproduction. Reproductive BioMedicine Online 23(5):555-564

47. Vatanoğlu-Lutz EE (2012) Research on embryos in Turkey with ethical and legal aspects. Journal of the Turkish German Gynecological Association 13(3):191

48. Serour Gl, Dickens BM (2001) Assisted reproduction developments in the Islamic world. International Journal of Gynecology \& Obstetrics 74(2):187-193

49. Knowles LP (2000) Science policy and the law: reproductive and therapeutic cloning. NYUJ Legis. \& Pub. Pol'y 4:13

50. Caulfield T (2001) Clones, controversy, and criminal law: a comment on the proposal for legislation governing assisted human reproduction. Alta. L. Rev. 39:335

51. Purvis TE (2015) Assisted reproduction in Indonesia: policy reform in an Islamic culture and developing nation. Reproductive biomedicine online 31(5):697-705

52. Shabana A (2017) Empowerment of women between law and science. Hawwa 15(1-2):193-218

53. Alahmad G, Al-Jumah M, Dierickx K (2012) Review of national research ethics regulations and guidelines in Middle Eastern Arab countries. BMC medical ethics 13(1):34

54. Inhorn MC, Birenbaum-Carmeli D, Tremayne S, Gürtin ZB (2017) Assisted reproduction and Middle East kinship: a regional and religious comparison. Reproductive biomedicine \& society online 4:41-51

55. Ghaly M, Sadoun E, Alkuraya F, Fakhro K, Ismail S, Ben-Omran T (2016) Genomics in the Gulf Region and Islamic Ethics. GENOMICS 4:01

\section{Publisher's Note}

Springer Nature remains neutral with regard to jurisdictional claims in published maps and institutional affiliations.

\section{Submit your manuscript to a SpringerOpen ${ }^{\circ}$ journal and benefit from:}

- Convenient online submission

- Rigorous peer review

- Open access: articles freely available online

- High visibility within the field

- Retaining the copyright to your article

Submit your next manuscript at $>$ springeropen.com 